\title{
95 Anos de Ensino de Sociologia no Ensino Médio
}

\author{
Michael DeCesare' \\ 'California State University-Northridge, Los Angeles-Estados Unidos da América
}

RESUMO - 95 Anos de Ensino de Sociologia no Ensino Médio. O centenário da Associação Americana de Sociologia, em 2005, oferece uma oportunidade para os sociólogos refletirem sobre o ensino de sociologia, em qualquer lugar e em todos os lugares que isso acontece. No espírito de contribuir para a história do ensino de sociologia nos Estados Unidos, este trabalho descreve a história de cerca de 95 anos do ensino de sociologia no Ensino Médio. Eu invoco descrições de cursos publicados escritos por professores de sociologia do Ensino Médio e estudos empíricos realizados por sociólogos acadêmicos. Eles demonstram que cursos de sociologia do passado do Ensino Médio têm focado principalmente na análise dos problemas sociais e os eventos atuais, e sobre a promoção da educação para a cidadania.

Palavras-chave: Ensino de Sociologia. História da Sociologia. Sociologia no Ensino Médio.

ABSTRACT - 95 Years of Teaching Sociology in High School. The American Sociological Association's centennial in 2005 affords sociologists an opportunity to reflect on the teaching of sociology - anywhere and everywhere that it happens. In the spirit of contributing to the history of teaching sociology in the United States, this paper outlines the roughly 95-year history of the teaching of high school sociology. I rely upon published course descriptions written by high school sociology teachers and empirical studies conducted by academic sociologists. They demonstrate that past high school sociology courses have focused primarily on examining social problems and current events, and on promoting citizenship education.

Keywords: Teaching Sociology. Sociology's History. Sociology in High School.

Educação \& Realidade, Porto Alegre, v. 39, n. 1, p. 113-137, jan./mar. 2014. 
Muitos sociólogos sabem que cursos de sociologia foram oferecidos em nível superior, pelo menos desde $1876^{1}$; poucos sociólogos percebem, no entanto, que a disciplina faz parte do currículo dos estudos sociais do Ensino Médio desde o ano letivo de 1911-1912 (Gillette, 1913). A parte negligenciada da história do ensino de sociologia no país é a história do ensino de sociologia no Ensino Médio. Apenas dois estudos empíricos foram publicados (Lashbrook, 2001; Rienerth et al., 1998) e duas dissertações escritas (DeCesare, 2004b; Dennick-Brecht, 2000) sobre o tema desde meados dos anos 1980. Em suma, quando os sociólogos falam e escrevem sobre ensino de sociologia, o que normalmente significa é o ensino de sociologia de nível universitário.

O centenário da Associação Americana de Sociologia (AAS), em 2005, ofereceu aos sociólogos a oportunidade de refletir sobre o ensino de sociologia - em qualquer lugar e em todos os lugares que isso acontece. No espírito de contribuir para uma história mais completa do ensino de sociologia nos Estados Unidos, este trabalho utiliza relatórios de pesquisa empírica e descrições de cursos de professores para traçar cerca de 95 anos de história do ensino de sociologia no Ensino Médio. Precisamos de uma história de cursos de sociologia no Ensino Médio, por pelo menos três razões. Primeiro, acredita-se geralmente que esses cursos têm existido apenas desde os anos 1960 (Lashbrook 2001), quando, na verdade, os dois primeiros cursos no país foram oferecidos durante o ano letivo de 1911-1912 (Gillette, 1913). Nós sabemos virtualmente nada sobre os primeiros 50 anos de existência do curso de Ensino Médio. Em segundo lugar, embora a AAS esteja mostrando um renovado interesse em melhorar os cursos de Ensino Médio, não está claro como extensivamente sua atual força-tarefa de implementação do curso avançado em Sociologia no Ensino Médio tem estudado as maneiras pelas quais, e os fins para os quais, a sociologia foi ensinada nas escolas ao longo do século XX. Eu argumento que os planos futuros, sejam estes da força-tarefa ou de algum outro grupo, devem ser baseados no conhecimento do passado. Finalmente, o conteúdo e os objetivos dos cursos de sociologia no Ensino Médio afetam diretamente a qualidade do ensino secundário, em geral, e do ensino de graduação em sociologia (DeCesare, 2002b), além do estado da disciplina como um todo (Bohlke, 1964; DeCesare, 2002a, Roberts; Piker-King, 1995; Seperson, 1994). Sociólogos fariam bem, então, ao examinar em detalhe como o conteúdo e os objetivos dos cursos de sociologia no Ensino Médio pareciam no passado e como podem ser no futuro.

\section{A História do Ensino de Sociologia no Ensino Médio Descrições dos Cursos de Professores}

F. D. McElroy e J. D. Bates ofereceram os primeiros cursos de sociologia no Ensino Médio do país durante o ano letivo 1911-1912 (Gille- 
tte, 1913). McElroy, um diretor de escola e professor em Hammond, Indiana, acreditava que "os princípios fundamentais da sociologia devem ser dados no curso", embora "algum tempo na última parte do curso deve ser dado à sociologia prática” (Gillette, 1913, p. 261). Ele usou dois manuais - Sociologia, de Dealey (que era "um pouco difícil e um pouco abstrato”, p. 261), e Sociologia Prática, de Wright - para chegar a esses dois aspectos do curso.

Bates, um professor em Jacksonville, Illinois, usava apenas um manual em seu curso de Sociologia: Sociologia e os Problemas Sociais Modernos, de Ellwood. De acordo com Hinkle e Hinkle (1954, p. 12), esse texto popular tratava a ciência sociológica e os papeis reformistas pela “[...] inter-relação, situando a aceitação de interesses meliorísticos com as outras pressuposições da lei natural, progresso e individualismo”. O próprio Bates descreveu a mais desejada característica de um manual:

[...] um eficaz e útil manual seria aquele que é simples e muito legível, apresentando ainda alguns dos fatos científicos subjacentes de forma legível... Um texto eficaz é aquele que vai manter o aluno interessado e que pode ser feito através da apresentação dos problemas sociais, como no de Ellwood (Gillette, 1913, p. 261).

Ambos, McElroy e Bates, queriam expor aos alunos os lados científicos e reformistas da sociologia, mas a fazê-lo em um "[...] caminho simples, definido, e não muito teórico” (Gillette, 1913, p. 261).

Essa abordagem dual provou ser a única entre os professores do Ensino Médio: todos os outros professores do Ensino Médio que publicaram uma descrição do curso antes da Segunda Guerra Mundial enfatizaram uma abordagem orientada pelos problemas sociais, enquanto minimizavam, ou ignoravam completamente, a sociologia como ciência.

Um desses professores foi W. G. Bate, um professor em Minnesota. Como J. D. Bates, Bate (1915) usava Sociologia e os Problemas Sociais Modernos, de Ellwood, porque ele acreditava que um manual "deve ser muito legível, escrito em estilo simples... e evitar as discussões mais abstratas, tanto quanto possível”. Acima de tudo, um manual de sociologia deveria lidar com "ilustrações concretas dos problemas" e não com "os princípios da ciência”. Na verdade, Bate afirmou claramente que "sociologia científica formal tem pouco lugar no curso de Ensino Médio”. Ele também escreveu apreciativamente que "Professor E. T. Towne da Faculdade $^{2}$ Carleton emitiu um esboço de um texto que promete ser quase inteiramente com base em exemplos concretos. O esquema não indica qualquer discussão sobre os princípios da ciência, exceto no resumo e na conclusão" (Bate, 1915, p. 332).

Os objetivos de Bate (1915, p. 332) para o curso foram “[...] despertar um interesse por parte dos alunos em problemas sociais existentes e sua relação com a vida, e desenvolver uma atitude social nas mentes das 
pessoas que fazem o curso". Para esses fins, esperava-se que os estudantes lessem um livro que tratava de um problema social, e preparassem um relatório escrito sobre o assunto. A tentativa de Bate de desenvolver em seus alunos uma "atitude social" indicava sua preocupação com o que viria a ser chamado de "educação cidadã”. Parte da promoção da educação cidadã era ensinar ética: "Na experiência do autor, o contato adquirido na aula tem sido a mais potente força na tentativa de realizar algum trabalho de ajuda pessoal e ensino de ética que é uma parte do dever de cada professor e diretor" (Bate, 1915, p. 336-337).

Em seu curso semestral, Bate oferecia um tratamento inicial da sociologia como disciplina, incluindo as razões para estudá-la e a sua definição; o curso mudou rapidamente para "o progresso e os problemas sociais" (Bate, 1915, p. 337). A maior parte do curso de Bate focava em problemas e patologias sociais. Ele dedicou o tempo de aula não só para uma discussão desses problemas, mas também para o seu "remédio", "prevenção", "tratamento”, ou “alívio” (veja o Anexo A para esboço do curso de Bate). No geral, o curso de Bate focava muito mais nos problemas sociais do que na sociologia científica; o seu objetivo era a moldagem de cidadãos dedicados à melhoria desses problemas.

No primeiro curso de Ensino Médio especificamente em sociologia rural, A. B. Buroker (1920) também explorou os problemas sociais e sua reforma, de olho no desenvolvimento de bons cidadãos. Ele tentou fazer com que seus alunos pensassem em maneiras de melhorar a sua comunidade de Ohio e apreciar o seu lugar dentro dela:

Muitos dos alunos, bem como os seus pais, estavam, ficou claro, sem uma apreciação das muitas coisas boas nas suas vidas da comunidade. Um conhecimento mais amplo das condições sociais ajudaria a torná-los mais satisfeitos com a sua própria sorte e estimulá-los para melhorá-la (Buroker, 1920, p. 151).

O manual que ele primeiro usou - Sociologia Rural Construtiva, de Gillette - tinha sido escrito para estudantes de nível universitário e provou ser muito difícil para os estudantes de Buroker. Então, ele lhes escreveu o seu próprio livro, escolhendo problemas que eram de interesse para eles. Quase como um aparte, Buroker (1920) afirmou que, salientando os problemas da comunidade, não força uma aproximação científica pela porta dos fundos: "Os princípios fundamentais que justificam a aplicação do termo ciência para estes estudos não foram negligenciados" (p. 152). Infelizmente, ele não entrou em detalhes sobre esses princípios.

Buroker (1920) concluiu com seis razões pelas quais ele acreditava que o curso foi um sucesso:

(1) O curso começou em casa, tanto mentalmente e geograficamente, na mente do pupilo e na cidade natal. (2) Tendo em conta problemas sociais maiores, uma tentativa 
foi feita para relacionar estes problemas com a situação local. As responsabilidades da unidade local para outras unidades e de outras unidades para a unidade local foi [sic] cuidadosamente considerada. (3) O costume de uma recitação de quarenta e cinco minutos em um determinado momento a cada dia não foi completamente seguido. Havia dias e dias quando os exercícios de aula ordinários foram omitidos, e os alunos passaram o tempo dedicado a esta aula para pensar e escrever. (4) Os pupilos descobriram que, coletivamente, eles tinham um grande estoque de informações valiosas. Alguns viveram em outras comunidades rurais, alguns em outros estados, e algumas cidades. Alguns trabalharam em fazendas, alguns em lojas, e alguns em comércios. Isto deu-lhes uma oportunidade de ajudar uns aos outros. (5) Pela primeira vez em suas vidas, eles se tornaram bem familiarizado com os seus próprios problemas sociais. (6) Eles ganharam confiança é [sic] seu próprio poder para fazer as coisas (p. 152).

Poucos aspectos dessa lista são dignos de nota. O primeiro é a ênfase em problemas sociais e sua reforma. Sociologia como ciência não é mencionada. A concretude e a relevância para os alunos do material do curso também são importantes. O foco de Buroker em problemas sociais de relevância para os alunos e concretude são semelhantes à ênfase de Bate (1915). Lembre-se que os dois últimos aspectos também foram importantes para McElroy e Bates (Gillette, 1913). Um último ponto é que Buroker impulsionou a educação cidadã - observe o destaque sobre as responsabilidades da "unidade local para outras unidades", e vice-versa, o seu foco na criação de uma oportunidade para que os alunos se ajudem mutuamente, e sua crença na importância da construção confiança dos alunos em seu "poder de fazer as coisas".

Como Buroker, Edward Dowell (1921), que era o professor de sociologia e diretor do departamento de ciências sociais na escola secundária de Bucyrus de Ohio, optou por não usar um manual. Ele aponta as razões por trás de sua escolha:

[Problemas Sociais] textos cobriram uma área muito limitada e foram particularmente deficientes do lado construtivo da vida social, faltando assim a coisa mais importante que um texto de Ensino Médio em sociologia deve ter. Os textos em sociologia destinados ao uso em faculdade colocaram muita ênfase em cima de teoria sociológica e outros assuntos não vitais para um curso de Ensino Médio (p. 318-319).

Um par de pontos deveria ser feito sobre esta citação. Dowell viu o estudo da sociologia e o estudo de problemas sociais como sinônimos. Na verdade, ele usou os títulos de curso Sociologia e Problemas Sociais alternadamente em seu artigo. Em segundo lugar, Dowell não gostou da ênfase dos livros da faculdade em teoria sociológica, pois viu teo- 
ria como desnecessário em um curso de sociologia do Ensino Médio. Os dois primeiros professores de sociologia do Ensino Médio, McElroy e Bates, também reservaram pouco espaço em seus cursos para a abstração ou teoria.

A fim de “[...] aumentar o interesse para o trabalho, bem como para dar aos alunos a oportunidade de ver em primeira mão como a sociedade cuida de alguns de seus desajustados" (Dowell, 1921, p. 322), Dowell organizou viagens de campo à cadeia local e ao condado de Almshouse, ao reformatório estadual, à penitenciária e ao hospital psiquiátrico e às escolas para surdos e cegos. Ele descreveu o objetivo e a preparação para essas viagens, utilizando a visita ao reformatório estadual em Mansfield como um exemplo:

\begin{abstract}
A viagem para Mansfield era para dar aos alunos uma concepção da forma em que jovens infratores são atendidos pelo Estado. Antes de ir para Mansfield várias lições foram dedicadas a uma reflexão sobre o problema do crime e do trabalho do reformatório em relação a este problema (Dowell, 1921, p. 322).
\end{abstract}

Obviamente, este não era um curso de sociologia científica. Em vez disso, Dowell ensinou sobre problemas sociais e o estudo e a observação do manejo de desajustados da sociedade - estes eram o que interessavam aos alunos.

O curso de Dowell foi um dos mais longos - e por várias considerações foi crescendo o número de ofertas de sociologia do Ensino Médio durante o início da década de 1920. Em 1921-1922, 25\% das escolas de todo o país relataram o oferecimento da sociologia para um total de 37.541 alunos (Grier, 1971). Outro estudo indica que mais de 50 mil estudantes tiveram sociologia durante esse ano (Angell, 1971; Hotchkiss, 1929). Independentemente dos números exatos, a tendência na época era claramente para um número crescente de cursos de sociologia no Ensino Médio em todo o país (Bain, 1926; Hotchkiss, 1929; West, 1930).

Florence Mason (1923) pensou em torno deste período, com uma descrição do seu curso de sociologia na Escola Secundária Jefferson, em Los Angeles. Ela teve dois objetivos fundamentais: “[...] desenvolver entre os alunos o sentimento de grupo e consciência, segundo, um ponto de vista sociológico" (p. 37). O primeiro incluiu “[...] desenvolvendo a ideia de como viver juntos e enfatizando o ponto que todos nós somos membros de grupos de trabalho para o bem dos seres humanos". Mason acrescentou que "[o] método de trabalho fora dessa ideia é um método científico” (p. 38), mas leia-se essa sentença solitária quase como uma reflexão tardia. A autora não entrou em detalhes sobre isso. Quanto ao ponto de vista sociológico, ele "[...] é desenvolvido, a fim de trazer a realização do fato de que há sempre dois ou mais lados da questão social e que falsas conclusões sobrepostas sobre premissas inadequadas podem retardar o progresso e causar dificuldades incalculáveis" (p. 38). 
Alguns dos alunos na aula de Mason formaram uma organização chamada, apropriadamente suficiente, de o Clube Utópico. Os alunos, como sua professora, provavelmente tinham em mente que o objetivo da educação “[...] é tornar melhores cidadãos de nossa juventude”, e que "o estudo da sociologia é um forte fator para realizar este fim" (Mason, 1923, p. 42-43). Tomados em conjunto, esses objetivos compreendem claramente a educação cidadã.

Sete anos mais tarde, E. E. Hawkins (1930) publicou uma descrição do curso de sociologia que ele estava ensinando na Escola Secundária Técnica Harrison de Chicago. Na época, Hawkins também estava fazendo um trabalho de pós-graduação, sob a orientação de Ernest W. Burgess, na Departamento de Sociologia da Universidade de Chicago. As influências de Burgess e da Escola de Chicago eram simples no curso de Hawkins. Na verdade, a ideia de Hawkins para os alunos de "trabalho de laboratório” era realmente de Burgess (Hawkins, 1930, p. 229) - o tratamento do departamento da cidade como um "laboratório social" é bem conhecido (Oberschall, 1972, p. 211). As práticas que Hawkins incentivava entre seus alunos durante o seu trabalho de laboratório foram projetadas para “[...] despertar a convicção da existência de problemas e desenvolver uma atitude simpática para com o trabalho para o bemestar social" (1930, p. 229). Por exemplo, em uma tentativa de estudar a pobreza e os esforços para aliviá-la, os alunos organizaram para terem cestas de alimentos entregues a famílias pobres locais durante a Ação de Graças. Eles também organizaram uma festa na escola para cerca de 300 crianças e pais que receberam ajuda do Departamento de Pensões das Mães. Os alunos participaram durante todo o ano nesses e em outros tipos de "caridade organizada", às vezes com a ajuda de um assistente social. Hawkins acredita que esse tipo de trabalho "[...] dá uma valiosa experiência na organização e responsabilidade e desenvolve uma cooperação mais inteligente em projetos para o bem-estar da comunidade" (Hawkins, 1930, p. 230).

Outra das atribuições de Hawkins estava diretamente relacionada com a maneira pela qual a sociologia foi praticada e ensinada na Universidade de Chicago. Tratava-se de cada aluno escrever uma história do quarteirão da cidade com a qual ele ou ela era mais familiar. O professor acreditava que esse exercício “[...] torna-se um meio valioso de ensinar o aluno a conhecer a sua comunidade e se interessar por seus problemas e crescimento" (Hawkins, 1930, p. 230). O autor escreveu que o próprio Burgess tinha usado a mesma tarefa em um de seus cursos universitários. É precisamente a influência acadêmica no curso de Hawkins que o torna tão interessante. Mesmo quando ele estava trabalhando sob um eminente sociólogo no departamento de sociologia mais forte e de maior prestígio no país, Hawkins ainda focava em ensinar os problemas sociais e sua reforma, e na promoção de educação cidadã, e não em expor os estudantes do Ensino Médio à sociologia científica.

Educação \& Realidade, Porto Alegre, v. 39, n. 1, p. 113-137, jan./mar. 2014 
No mesmo ano em que o artigo de Hawkins (1930) apareceu, R. C. Hurd (1930) publicou uma descrição de como ele estava ensinando "Sociologia, por Projeto e Problema” na Escola Secundária Waukegan Township, em Illinois. Os dois primeiros projetos foram jogos de classe que "[...] dinamizaram o problema da imigração e americanização" (Hurd, 1930, p. 265). Além disso, os estudantes tiveram duas aulas de pesquisas. A primeira delas teve novamente como objetivo estudar "o problema da imigração e americanização”, enquanto a segunda estudou as "práticas e atitudes sociais" dos alunos (p. 266). Hurd conclui seu artigo com uma afirmação da importância da sociologia:

Para aqueles que estão planejando entrar em alguma vocação ao término do Ensino Médio [sociologia], abasteçam-se pelo menos de um conhecimento prático dos nossos principais problemas sociais, o que é um valor considerável para eles como cidadãos e para a comunidade em que estão a viver (Hurd, 1930, p. 266).

Como antes, a ênfase de Hurd é em problemas sociais e educação cidadã.

Para O. S. Flick (1933, p. 255), da Escola Técnica do Arsenal em Indiana, o propósito de estudar sociologia e outras ciências sociais "encontra-se expresso como um dos sete princípios fundamentais do ensino secundário, o de preparação para a cidadania”. Apesar dessa ênfase na educação cidadã agora ser familiar, Flick foi o primeiro para torná-la explícita e descrever o que isso implicava. Parte disso estava em manter a "atitude correta" para com os outros: "A atitude correta é um dos entendimentos e respeito por essas relações que todos nós herdamos do passado por termos nascido neles" (p. 256). O objetivo do ensino de estudos sociais, e, ao fazê-lo, "[...] transmitir as informações que levam a compreensão e respeito, [é que] o professor pode implantar no aluno, ao mesmo tempo um senso de responsabilidade para a melhoria" (p. 256). Em suma, Flick argumentou que os três objetivos principais de ensinar cidadania no contexto dos estudos sociais foram o aumento do entendimento, do respeito e da responsabilidade.

A melhor maneira de ensinar cidadania efetiva e suas características, Flick (1933, p. 259) afirmou, era escolher materiais que eram "[...] do ambiente dos alunos e sob a sua visão, não tecnicamente tratados, [e] em grande parte em forma de problema”; esta foi claramente a abordagem feita pelo professor de sociologia do Ensino Médio para este ponto. O valor da sociologia, de acordo com Flick, estava em “[...] apontar o caminho para melhores coisas na nossa composição social e, sobretudo, em dar ao aluno o ponto de vista social ou de grupo" (Flick, 1933, p. 259). Esses sentimentos resumem bem a abordagem adotada pelos professores que vieram antes dele.

Em 1938, J. Dyer, um professor de sociologia em Chattanooga, Tennessee, publicou um ensaio sobre Instrução de Sociologia Vitalizan- 
te. O curso de sociologia de Dyer era essencialmente um curso de problemas sociais, em que "[...] o objetivo era ensinar sobre pessoas vivas, coisas vivas, e as questões da vida” (1938, p. 19). Nenhuma menção é feita de sociologia científica. O curso inteiro girava em torno de uma exigência: cada aluno "selecionar uma investigação especial, estudo e pesquisa de um problema social” (p. 19). O principal desses problemas eram as relações raciais.

Durante a década de 1930, tanto o número de cursos de sociologia quanto a percentagem de escolas que ofereciam sociologia continuaram a aumentar (Kercher, 1938). Em 1934-1935, apenas 111.718 alunos (2,5\% de todos os estudantes do Ensino Médio) estavam matriculados em um curso de sociologia (Grier, 1971). A popularidade da Sociologia entre os estudantes do Ensino Médio foi crescendo.

Refletindo essa tendência, Nourse e Brown (1940) salientaram a necessidade da introdução de sociologia para estudantes do Ensino Médio, e resumiram o material sociológico que estava sendo ensinado no sétimo ano em Los Angeles através do programa de estudos sociais. Era preciso ensinar sociologia, de acordo com os autores, porque "[...] é mais necessário que a juventude seja levada conscientemente para o desejo de ajudar a comunidade. Eles devem ser 'bons' no sentido mais amplo. Para atender a essa necessidade, a juventude deve ter o máximo de conhecimento possível sobre suas comunidades" (Nourse; Brown, 1940, p. 411). Presente nessa concepção da finalidade da sociologia é a mesma ênfase sobre a reforma da comunidade e educação cidadã que marcou as concepções dos professores anteriores.

Também em 1940, Wayne Swinton, um professor na Escola Secundária Galesburg, em Illinois, publicou uma descrição do seu curso de sociologia. Ele deu apenas de passagem a atenção para os objetivos do curso: "O objetivo fundamental do ensino da sociologia é o desenvolvimento de interesse e de atitudes adequadas relativas às instituições sociais significativas e problemas" (Swinton, 1940, p. 9). Ensinar sociologia “[...] será eficaz em grande parte, na medida em que [o procedimento utilizado] permitir que o aluno participe ativamente da análise de um problema de interesse vital para si mesmo" (Swinton, 1940, p. 9). Mesmo nessas breves declarações podemos ver o objetivo de educação cidadã e o foco pontual sobre problemas sociais.

De maior consequência para Swinton foram os melhores métodos para alcançar essas metas. Manuais não eram um deles, ele acreditava, o que o colocava em companhia de outros professores de sociologia anteriores (Buroker, 1920; Dowell, 1921). Embora ele admitisse que "[...] sociologia não sofreu tão extensivamente como os outros estudos sociais a partir da inclusão da teoria e da outra matéria indesejável nos materiais básicos”, ele passou a escrever que “[...] manuais no mercado hoje... têm nada além de pouca consideração para habilidades de leitura do estudante, experiências sociais ou interesses" (Swinton, 1940, p. 8-9).

Educação \& Realidade, Porto Alegre, v. 39, n. 1, p. 113-137, jan./mar. 2014. 
A semelhança percebida entre "teoria" e "matéria indesejável" é digna de nota, do mesmo que considerou Dowell (1921). Ele também está em sintonia com a ênfase de quase todos os outros professores do Ensino Médio na relevância e concretude, ao invés de abstração e imprecisão. Simplificando, a teoria social era "indesejável" porque era muito abstrata.

Então, em vez de depender exclusivamente de um manual, Swinton (1940) utilizou uma variedade de materiais e uma variedade de técnicas de ensino de leitura. Uma "biblioteca de referência eficaz", juntamente com "materiais atuais", formou a espinha dorsal do curso. A primeira incluía uma bibliografia de "assuntos que possam ser de interesse vital para um cidadão ativo de uma democracia"; pobreza, problemas trabalhistas, religião e moral, e raça estavam entre eles (Swinton, 1940, p. 9).

Onze anos depois de publicar seu artigo sobre Instrução de Sociologia Vitalizante, J. Pope Dyer (1949) discutiu a "modernização do ensino da sociologia". No sentido de modernizar seu curso de sociologia (ou seja, para torná-lo "interessante", "significativo" e "funcional"), ele usou as transmissões de rádio e "fóruns", ou discussões em classe. "O fórum", escreveu Dyer, "é um dos melhores meios de garantir o interesse e, incidentalmente transmitir conhecimentos" (1949, p. 305). Este é um comentário dito. Para Dyer, "vitalizar" e "modernizar" a sociologia dependia, em grande parte, de torná-la mais interessante para os alunos e, por sua vez, permitir que a aprendizagem dos alunos ocorra por acaso.

De acordo com Bruce Watson, um professor secundário de sociologia da Califórnia, escrevendo em meados da década de 1950, a importância da sociologia para os alunos não veio da "[...] frequente regurgitação inane de um manual", mas, sim, da "análise de problemas persistentes" (Watson, 1955). Ele acreditava que isso era importante, e viu isso como senso comum, que as abordagens sociológicas para os problemas sociais fossem "vazias, é claro, de sua linguagem técnica" (Watson, 1955, p. 177). Não existe uma teoria aqui, e nenhuma menção de ciência, apenas uma consideração de problemas da vida real enfrentados pelos alunos, suas famílias e suas comunidades. Não surpreendentemente, Watson acreditava que esta consideração seria incompleta sem uma discussão de "movimentos de reforma social" (Watson, 1955, p. 177). Em suma, o curso se parecia muito com aqueles que vieram antes dele.

Em 1959, Arthur Repke, um professor de escola na Flórida, ofereceu uma perspectiva completamente diferente sobre o propósito de ensinar sociologia. Ele insistiu que "os aspectos normais da vida social", juntamente com "princípios científicos" da sociologia, fossem ensinados em cursos de sociologia do Ensino Médio. O objetivo final era ainda uma reforma do mundo social: "O problema mais importante que a humanidade enfrenta é o de melhorar o ambiente social para que ela 
desenvolva tipos progressivamente superiores de pessoas que, por sua vez, criam uma ordem social cada vez mais eficaz" (Repke, 1959, p. 37). No entanto a única maneira de os alunos poderem compreender o mundo social e participarem na mudança era "para estudar o corpo de princípios válidos e conhecimento objetivo que a sociologia tem a oferecer" (Repke, 1959, p. 38). Essa concepção científica da sociologia não tinha sido ouvida entre professores do Ensino Médio nos primeiros 50 anos (Gillette, 1913).

Ainda assim, por toda a sua ênfase em uma abordagem sociológica objetiva e científica, Repke (1959, p. 40) também subscreveu muitos dos mesmos objetivos do curso aos quais outros professores aderiram:

(1) para conhecer as várias disciplinas sociais e seus campos especiais de investigação, (2) para perceber que toda a vida humana é de vida em grupo e que a cooperação e compreensão são necessárias para viver juntos, (3) para dar uma bem-arredondada e equilibrada visão da vida, (4) para reduzir o preconceito e promover a compreensão por meio de realização de que as diferenças individuais e de grupo são em grande parte o resultado de diferenças nas experiências de vida, (5) a perceber que os problemas sociais são apenas o reflexo de instituições defeituosas, e que um julgamento equilibrado dos problemas sociais e da reforma social só podem ser entendidos em termos de mudança social; (6) para aprender a examinar criticamente todas as panaceias, propaganda, slogans e movimentos de soerguimento, substituindo o pensamento emocional, romântico e desejo com hábitos de pensamento realista.

Há um par de temas familiares aqui. Um deles é a educação cidadã, que inclui a compreensão, a tolerância e a cooperação; a segunda é a abordagem dos problemas sociais. Mas também vemos algo diferente na concepção de Repke da sociologia. A ênfase nos itens 1 e 6 está em conhecer as disciplinas acadêmicas e seus métodos de investigação, e usá-los para promover habilidades de pensamento crítico.

Repke (1959) foi um dos poucos professores de sociologia antes de 1960 a afirmar sua crença no "[...] valor do método científico como um instrumento para uma melhor compreensão do mundo social” (p. 41). A grande maioria dos cursos de sociologia do Ensino Médio antes de 1960 foi oferecida clara e principalmente preocupada com a existência, a perpetuação e a melhoria dos problemas sociais, e com incentivo à educação cidadã. O objetivo principal por trás dessa abordagem foi a de acender o interesse do aluno, tornando o material relevante a "revitalizar" e "modernizar" a sociologia, como Dyer $(1938,1949)$ colocou.

James Schall (1965) publicou uma descrição detalhada de um curso de sociologia do Ensino Médio, enquanto ele serviu como presidente da divisão de sociologia do departamento de estudos sociais na Escola Secundária Senior Upper Darby, na Pensilvânia. Embora a maior parte 
do texto seja uma declaração do sucesso de seu curso, como indicado por um grande número de matrículas de estudantes, o conteúdo sociológico do discurso de formatura de sua escola secundária, bem como a longevidade da declaração de seus objetivos do curso de sociologia, a afirmação de Schall é ilustrativa de vários temas familiares:

\begin{abstract}
Nossos objetivos são conseguir uma valorização real de valores e problemas humanos, sua origem, desenvolvimento e possível solução, para alcançar uma apreciação significativa e compreensão da nossa própria cultura, nossos pontos fortes, pontos fracos, problemas atuais, e possível futuro, [e] para alcançar uma compreensão significativa da interdependência e vulnerabilidade de todos os povos em um mundo encolhido em uma era atômica... (Schall, 1965, p. 296).
\end{abstract}

Embora a afirmação de Schall refira-se à sociologia como “[...] a ciência e a arte das relações humanas”, não está claro a partir dos objetivos do curso que essa concepção enquadrou o curso (Schall, 1965, p. 296). Sua ênfase na educação cidadã, nos problemas sociais e na reforma, e na relevância para os alunos é a mesma que as dos professores do Ensino Médio anteriores.

O foco de Schall (1965) nos problemas sociais e na reforma é evidente a partir de uma análise de seu esboço de curso (o tempo dedicado a cada unidade está entre parênteses):

Unidade 1. Introdução (uma semana), unidade 2. Psicologia e Psicologia Social (seis semanas), Unidade 3. Estrutura Social e Sistema de Classe (duas semanas), Unidade 4. A família (quatro semanas), Unidade 5. Cultura (cinco semanas), Unidade 6. Problemas Sociais (nove semanas), Unidade 7. Religião (sete semanas), Unidade 8. Reconstrução Social (duas ou três semanas) (Schall, 1965, p. 297).

Alguma ampliação desta lista está em ordem. A Unidade 2 foi dedicada quase que inteiramente ao estudo da psicologia. A unidade de cinco semanas em cultura era, por própria confissão do autor, “[...] realmente uma apresentação dos conceitos básicos de antropologia física e cultural" (Schall, 1965, p. 297). A unidade sobre religião foi informada, não só pelo conhecimento antropológico, mas também pela psicologia. Relativamente pouca sociologia, então, foi apresentada durante as 18 semanas dedicadas a estas três unidades (2, 5 e 7). Apenas uma semana, a primeira do ano, foi dedicada a uma "Introdução à Sociologia" (p. 297). Mas na mesma semana também incluiu discussões sobre requisitos e procedimentos do curso e "atitudes desejadas pessoais e relações interpessoais dentro da classe" (p. 297). Das restantes 17 a 18 semanas do curso, de 11 a 12 semanas foram dedicadas à análise dos problemas sociais e de reconstrução. Em vez de oferecer um curso de sociologia científica, enfatizou os problemas sociais e a reforma, juntamente com uma mistura de psicologia e antropologia. 
Em 1970, e como uma involuntária síntese da frustração que muitos professores anteriores do Ensino Médio tinham sentido relativamente ao padrão dos manuais introdutórios (Buroker, 1920; Dowell, 1921; Roberts, 1968; Swinton, 1940), o professor secundário Jhon Fuchs, de Nova York, forneceu uma bibliografia comentada de "livro de bolso legível de valor de \$100 para sociologia do Ensino Médio”. Como muitos professores antes dele, Fuchs (1970, p. 57) veio a perceber, enquanto ensinava sociologia, que "[...] a parte mais fraca do meu programa foi a falta de interesse, claramente, livros escritos relevantes com conteúdo sociológico substancial". Fuchs também tentou, como seus antecessores, construir uma biblioteca de livros que introduziriam o material da sociologia conceitual. Vale ressaltar que seu objetivo na escolha de livros era "[...] desafiar a mente jovem e introduzir ao aluno pontos provocadores de análise abrangente, em vez de 'cobrir' esta enorme disciplina" (Fuchs, 1970, p. 57).

Fuchs (1970) incluiu muitos clássicos em sua lista; ele estava obviamente familiarizado com os trabalhos sociológicos mais importantes dos últimos 15 anos, mais ou menos. Não só isso, mas ele forneceu títulos, datas e descrições avaliativas mesmo breves de diversos autores, outros mais recentes, e obras (veja o Anexo B para uma lista dos 29 livros de bolso recomendados).

Por outro lado, Fuchs (1970) listou relativamente poucos livros sobre teoria e pesquisa, os dois pilares da sociologia científica. O livro de Cuzzort (1969) é o único da lista que fornece uma visão geral de teóricos importantes. E apenas dois livros lidam formalmente com a prática de pesquisa sociológica: Hammond (1964) e Thomlinson (1965). Finalmente, a inclusão do livro de Madge (1962) sobre as origens da sociologia científica vale a pena mencionar. A anotação de Fuchs para este trabalho está dizendo que leva em conta duas questões: "A verdadeira surpresa é que [Madge] trata o seu assunto em um estilo conciso, agradável e animado... uma referência ideal para o professor com pouca formação em sociologia” (Fuchs, 1970, p. 64). Em primeiro lugar, o livro de Madge em sociologia científica é importante e incomum para Fuchs simplesmente por causa de seu estilo acessível. Em segundo lugar, ele menciona que seria útil para os professores não familiarizados com a sociologia. Os pressupostos implícitos aqui são de que esses professores existem e que constituem um grupo grande o suficiente para justificar o comentário.

\section{Pesquisas Empíricas}

Infelizmente, as descrições dos cursos escritos por professores desapareceram depois do ensaio de Fuchs (1970). Temos vários estudos empíricos, no entanto, para nos ajudar a completar a história dos cursos de sociologia do Ensino Médio.

Educação \& Realidade, Porto Alegre, v. 39, n. 1, p. 113-137, jan./mar. 2014. 
Read Bain (1926), na primeira investigação empírica realizada por um sociólogo sobre sociologia no Ensino Médio, destacou a ênfase dos professores sobre os problemas sociais e de educação cidadã naquele momento. A popularidade dessa abordagem particular poderia ser vista na opinião dos professores sobre os valores obtidos pelos alunos ao estudar sociologia. Esses valores e o número de professores que expressaram cada um estão reproduzidos no Quadro 1, abaixo. Bain acreditava que a abordagem generalizada dos problemas sociais foi prejudicial para os alunos. Sua crença o levou a concluir que a sociologia no Ensino Médio estava em um estado deplorável, e ele sem rodeios expressou seu desejo de que "[...] a sociologia verdadeira seja ministrada por professores com formação adequada no lugar do sentimentalismo ilegível e radicalismo superficial" (p. 542) que caracterizava os cursos de sociologia secundária no momento.

Tabela 1 - Os valores obtidos por alunos de um estudo de sociologia $(\mathrm{N}=133)$

\begin{tabular}{|l|c|}
\hline & Frequência \\
\hline $\begin{array}{l}\text { Socialização (relações de grupo, a estrutura social, simpatia } \\
\text { social) }\end{array}$ & 38 \\
\hline Melhores cidadãos & 29 \\
\hline Interesse e inteligência em problemas sociais & 25 \\
\hline Amplia a visão & 16 \\
\hline Ética (direitos, deveres, responsabilidades) & 14 \\
\hline Equilíbrio e adaptação à vida & 9 \\
\hline Auxilia na seleção de parceiros adequados & 1 \\
\hline Aumenta a eficiência nos negócios & 1 \\
\hline
\end{tabular}

Fonte: Bain (1926, p. 536)

Bain (1926) passou a relatar que, entre 1920 e 1924, o número de escolas que ofereciam sociologia tinha aumentado em mais de $90 \%$, e que o número de alunos que participavam de cursos de sociologia tinha aumentado em quase $160 \%$. Sentia-se que as perspectivas de um aumento contínuo foram boas, apesar da existência do que ele viu como um grande problema: a grave escassez de professores com formação adequada. Nenhum professor em sua amostra tinha se formado em sociologia e quase metade nunca havia feito um curso de sociologia.

Quatro anos depois, na primeira tese de doutorado sobre sociologia no Ensino Médio, West (1930, p. 20) também observou que "[...] a sociologia está ganhando ao entrar no campo do ensino secundário" 
e concluiu que não havia muito interesse na disciplina. West observou como um ponto adicional que os problemas sociais eram mais frequentemente o foco dos cursos de sociologia do Ensino Médio do que "considerações básicas na disciplina" (West, 1930, p. 75).

Leonard Kercher (1938), escrevendo oito anos após West (1930), estudou os cursos de sociologia oferecidos em pequenas e grandes escolas de Michigan. Ele constatou que, em $56 \%$ da primeira e 59,5\% desta última, a ênfase foi colocada sobre problemas sociais. "Teoria e problemas" foram sublinhados em um adicional de $36,5 \%$ e $25 \%$ das escolas, respectivamente. Teoria só apareceu em apenas $2 \%$ das grandes escolas e $12 \%$ das pequenas escolas.

As conclusões de Kercher (1938) em relação aos objetivos do curso e à qualificação dos professores contradizem Bain (1926), uma década antes. Bain tinha achado que o objetivo da maioria dos cursos foi a reforma social e que a maior parte dos cursos estava focada em condições patológicas. Por outro lado, Kercher (1938, p. 427) concluiu que “[...] um esforço verdadeiro estava sendo feito para orientar os alunos em um estudo objetivo da observação de instituições e condições sociais em sua comunidade local, com atenção sobre as relações normais de vida ali existentes, bem como sobre as situações patológicas definitivamente". Quanto às qualificações dos professores, Bain (1926, p. 542) concluiu que havia uma "falta de professores devidamente preparados para ensinar sociologia", em Washington. Kercher (1938, p. 435), por outro lado, constatou que os professores Michigan seriam "um grupo competente e alerta".

É difícil entender como Kercher (1938) desenhou suas conclusões, dadas as respostas dos professores ao seu questionário. Nas palavras do próprio autor, as respostas dos professores "[...] revelam a ênfase marcante sobre os problemas de adaptação personalidade... [e] evidenciam a confusão das funções da sociologia como ciência social com as da ética e da religião". Um "problema de ênfase também é claramente perceptível" em muitos cursos (Kercher, 1938, p. 429). Aqui, a sociologia “[...] preocupa-se em grande parte com a natureza dos problemas sociais e com certas atitudes e técnicas para ajustá-los" (Kercher, 1938, p. 430). Parece, então, que os resultados de Kercher (1938) são mais semelhantes aos de Bain (1926) e às interpretações oferecidas aqui do que suas conclusões sugerem.

Outro estudo empírico sobre sociologia no Ensino Médio não aparece até 40 anos depois, quando Marlene Weber (1978) realizou um levantamento dos cursos de sociologia do Ensino Médio e professores em Wisconsin. Mais da metade $(57,2 \%)$ dos cursos estava focada exclusivamente em problemas sociais ou em uma combinação de problemas sociais e sociologia. Além disso, apenas "cerca de um quarto" dos professores tinha ganhado suficientes créditos de graduação para igualar um menor ou maior grau em sociologia; muitos professores não cumpriam 
as exigências do estado. Weber sugeriu que "[...] o foco sobre os problemas sociais... pode ser uma tentativa para resolver este problema" da formação de professores inadequada em sociologia (Weber, 1978, p. 13).

Em 1981-1982, 14,3\% dos alunos do Ensino Médio foram fazer um curso de sociologia (Switzer, 1986, p. 126). Nesse momento, e como acompanhamento para o estudo de Weber (1978), Kraft (1981) pesquisou os professores de sociologia do Ensino Médio de Wisconsin. Ele descobriu, primeiro, que $67 \%$ dos cursos levaram o título de "Sociologia", mas que apenas $27 \%$ deles sublinharam "a sociologia como [a] disciplina científica"; os outros 73\% enfatizaram problemas sociais, relações interpessoais práticas ou alguma outra abordagem (Kraft, 1981, p. 67).

Kraft (1981) também pediu que os professores classificassem seus objetivos de curso em uma escala de cinco pontos ( 5 = máximo de ênfase, 1 = mínimo de ênfase). Aqui está uma lista das metas (com classificações médias e o percentual de professores que avaliaram cada uma com 4 ou 5):

(1) para fornecer uma maior consciência dos processos sociais e culturais que influenciam o cotidiano das pessoas (4,27, 79\%), (2) obter uma maior tolerância das diferenças entre povos e culturas, através de uma diminuição da etnocentrismo do aluno (4.24, 79\%), (3) obter uma maior sensibilidade para as diferenças e semelhanças em grupos, sociedades e culturas $(4,20,81 \%)$, (4) obter uma maior compreensão das questões complexas e éticas envolvidas em muitos sociais problemas (3,62, 57\%), (5) desenvolver a habilidade de usar técnicas de pesquisa social $(2,31,12 \%)$.

O resultado mais notável aqui é a quinta meta. O único objetivo que enfatiza claramente a sociologia científica recebeu a menor média de classificação de longe (2,31), e apenas $12 \%$ dos professores classificou sua ênfase com 4 ou 5 . As outras quatro metas muito mais comuns giram em torno de problemas sociais e da educação cidadã. Kraft concluiu que, pelo menos em escolas de Wisconsin, havia uma "falta de ênfase sobre a natureza científica da sociologia", em favor de uma abordagem de problemas sociais (1981, p. 71).

Inexplicavelmente, os trabalhos publicados nos quase 25 anos, desde o artigo de Kraft, têm falado pouco sobre o conteúdo e os objetivos dos cursos de sociologia do Ensino Médio. Eles têm se concentrado principalmente em demonstrar que os professores de sociologia tiveram pouco treinamento ou educação na disciplina. Short e Matlock (1982), por exemplo, constataram que apenas um em cada cinco professores em sua amostra nacional relatou formação acadêmica em sociologia, apenas 7\% realizaram uma pós-graduação na área. Quatro anos mais tarde, Short, Matlock e Watts (1986) e Short, Watts e Matlock (1986) concluíram que os professores do Ensino Médio de sociologia no Texas não foram bem preparados para ensinar a disciplina. Mais da metade dos professores $(54,2 \%)$ tinha menos de 13 horas por semestre de so- 
ciologia na graduação. Apenas 14,5\% tinham ganhado o equivalente a uma graduação na disciplina, que era de 30 horas ou mais. No mesmo ano, Dorn (1986) entrevistou 20 professores de sociologia da Califórnia, dos quais 10 tinham tomado menos de quatro cursos de graduação em sociologia e nenhum com formação em sociologia.

A próxima onda de estudos empíricos sobre cursos de sociologia do Ensino Médio e professores não chegou até 12 anos mais tarde, e os resultados foram os mesmos. Todos os quatro estudos realizados entre 1998 e 2004 compartilharam uma conclusão: os professores de sociologia estavam mal preparados para ensinar a disciplina (DeCesare, 2004b; Dennick-Brecht, 2000; Lashbrook, 2001; Rienerth et al., 1998). A pesquisa de DeCesare $(2004 \mathrm{~b}, 2005)$ foi um pouco mais longe por sondagem - desde Kraft (1981), pela primeira vez isso foi feito - ao conteúdo e aos objetivos dos cursos de sociologia no Ensino Médio. Os resultados indicaram que os professores de sociologia em Connecticut ofereceram pouco no caminho da sociologia científica. Em vez disso, eles promoveram educação cidadã através da análise dos problemas sociais e de algumas possíveis soluções.

\section{Especulações para o Futuro}

Dado o panorama histórico apresentado acima, qual é o futuro provável que se mantenha para o ensino de sociologia no Ensino Médio? Com base na minha leitura de sua história de 95 anos, ofereço as quatro seguintes previsões:

1) Os cursos de Sociologia continuarão a se concentrar principalmente sobre os problemas sociais e os eventos atuais, e em realizar a educação cidadã como o objetivo principal do curso.

Uma das principais razões pelas quais os professores têm tradicionalmente escolhido o conteúdo e os objetivos que eles têm, e por isso que eu acredito que eles vão continuar a fazê-lo, é puramente pragmática: eles precisam considerar o que será de interesse e parece ser relevante para os alunos do Ensino Médio. Sem rodeios, os alunos estão mais interessados em problemas sociais que eles já estão familiarizados do que em teoria sociológica ou métodos de investigação. Entre os assuntos abordados no Ensino Médio, quais são mais relevantes e interessantes para os alunos do que os problemas sociais em suas próprias comunidades? Provavelmente, não muitos, e certamente não os princípios de uma disciplina científica vagamente definidos. Não há nenhuma razão para pensar que os interesses dos alunos vão mudar tão cedo.

Falta de treinamento formal dos professores e a exposição profissional para a disciplina é a segunda razão pela qual eles têm tido uma abordagem dos problemas sociais. A maioria dos professores do Ensino Médio provavelmente nunca aprendeu muito, ou nada, sobre a teoria sociológica, os métodos de pesquisa, ou aspirações científicas da sociologia. Parece irrazoável, portanto, esperar que eles ensinem os aspectos 
da disciplina. Por outro lado, todo mundo que lê as notícias de jornais ou revistas, ou vê televisão, está familiarizado com os problemas sociais e os eventos atuais. Parece que os professores, centrando-se sobre os problemas sociais, estão ensinando aquilo com o que eles estão mais familiarizados. Eu prevejo que eles vão continuar a fazê-lo.

Isso me leva a uma segunda previsão:

2) Os cursos de Sociologia continuarão a ser oferecidas por professores que têm pouca instrução em, experiência com ou exposição à sociologia acadêmica.

É extremamente improvável que os professores atuais começarão voluntariamente a buscar mais instrução ou profissionalização em sociologia. Por 95 anos, professores de sociologia foram ensinando aquilo com o que eles estão confortáveis: eventos atuais e de cidadania. Além disso, eles ensinam diversos assuntos e não têm tempo, dinheiro ou disposição para passar por um desenvolvimento profissional extenso em qualquer um deles (DeCesare no prelo). Devemos lembrar que eles normalmente ensinam sociologia uma ou duas vezes por ano, por um período por dia. Comparado com quanta história eles ensinam, por exemplo, os professores gastam uma quantidade muito pequena de tempo pensando ou ensinando sociologia.

É tão improvável quanto que os distritos escolares ou colégios começarão impondo mais exigências de cursos de sociologia sobre os futuros professores do Ensino Médio. A fim de serem certificados para ensinar estudos sociais, os futuros professores devem passar por um exame de domínio dos conteúdos, que abrange principalmente a história. Dentro de faculdades de educação, então, não há motivo para exigir de futuros professores de estudos sociais que dominem outros assuntos além da história. Além disso, o simples fato é que a grande maioria dos professores de estudos sociais é contratada para ensinar outros cursos além da sociologia, especialmente história e civismo. Em algum ponto durante os estudos sociais na carreira dos professores, a sociologia simplesmente é adicionada à sua agenda (Dennick-Brecht, 2000). Praticamente ninguém se torna um professor de estudos sociais especificamente para ensinar sociologia.

Uma questão relacionada tem a ver com os padrões acadêmicos criados para as várias disciplinas de estudos sociais pelas secretarias estaduais de educação. Sem rodeios, os administradores escolares são muito mais propensos a oferecer cursos que ajudam os alunos a cumprir as normas estaduais. Na maioria das vezes, cursos de história e civismo fazem isso, sociologia não. Considere a Pensilvânia como um exemplo. O Departamento de Educação do estado criou normas só para educação cívica e governo, economia, geografia e história. Não existem padrões para a sociologia. Portanto os administradores provavelmente não acreditam que há muita necessidade de ensiná-la, afinal os alunos não têm que atender a qualquer tipo de normas estaduais na disciplina ${ }^{3}$. 
Talvez percebendo algumas dessas questões, o Comitê da AAS de Sociologia nas escolas primárias e secundárias, que existiu entre 1989 e 1998, elaborou três moções. A primeira afirmou que, para "estar certificado para ensinar 'sociologia', os professores do ensino secundário deveriam ter pelo menos nove horas de crédito do curso de sociologia" (Levine, 1997, p. 2). Keith Roberts e Barbara Karcher, os copresidentes do Comitê, enviaram-na para o Departamento de Educação de cada estado e pediram às associações sociológicas regionais e estaduais para formarem forças-tarefa sobre a sociologia no Ensino Médio. Seu trabalho seria fazer lobby com as legislaturas estaduais para implementar a política. Os copresidentes também sugeriram que as associações sociológicas locais desenvolvessem oficinas para professores do Ensino Médio (ver Dennick-Brecht, 2000, Apêndice B, para obter uma cópia sobre Roberts e a carta de Karcher às associações regionais). Ao meu conhecimento, pouco tem sido feito em cada frente.

A segunda e a terceira moções do Comitê de 1989 afirmam "que a AAS deve iniciar a discussão de um exame de Localização Avançado $(\mathrm{LA})^{4}$ com o College Board ${ }^{5}$... e que a Comissão deve desenvolver padrões de cursos para a 12a série eletiva" (Levine, 1997, p. 2). Essas moções só recentemente começaram a ser realizadas por um novo grupo, nomeado, em 2001, a Força-Tarefa AAS no Curso de Localização Avançada (LA) de Sociologia no Ensino Médio.

Minha terceira previsão refere-se às recomendações feitas por este grupo até o momento:

3) O trabalho da atual Força Tarefa da AAS no Curso de LA irá partilhar o destino das recomendações feitas pelos comitês passadas e forçastarefa; será visto por professores do Ensino Médio como irrelevante e será ignorado.

Não é apenas que os professores de estudos sociais gastam uma quantidade relativamente pequena de tempo ensinando sociologia. É também que suas decisões sobre o conteúdo e os objetivos do curso são constrangidos pelos grandes objetivos do currículo de estudos sociais. Parece que a partir da proposta curricular da Força Tarefa (ver Associação Americana de Sociologia, 2004), e sua forte ênfase em sociologia científica, o grupo tem negligenciado este ponto (ver DeCesare, 2004a para uma crítica detalhada do currículo de LA).

Educação cidadã e o cultivo de valores democráticos foram os dois objetivos do currículo de estudos sociais desde que foi formalizada pela primeira vez, na esteira da Guerra Civil. Os primeiros sociólogos certamente estavam cientes deste ponto. Hayes (1923, p. 419), por exemplo, comentou sobre a "demanda insistente e generalizada entre as autoridades das escolas públicas... para proporcionar uma preparação mais adequada para a cidadania". Como vimos, a maioria dos professores do Ensino Médio também tem reconhecido esses objetivos curriculares tradicionais e teve pouco incentivo para mexer com eles. Eu não sou otimista sobre a capacidade da AAS para mudar isso. 
Claro que o currículo de estudos sociais do Ensino Médio em si é parte de grandes contextos históricos e sociais. Para uma indicação de seu impacto sobre os currículos e cursos, basta olhar para os contornos dos cursos passados e atuais dos professores de sociologia. Para dar um exemplo, faria pouco sentido incluir seções sobre Problemas com Bebidas ou sobre Trabalho Infantil em um curso oferecido em 2005; elas fizeram muito sentido, no entanto, para incluir esses temas durante a Lei Seca e sob condições de trabalho infantil e exploração generalizada neste país (Bate, 1915). Da mesma forma, teria sido impossível, ou pelo menos impraticável, para os professores dos anos 1950 terem incluído seções do curso sobre o casamento gay ou o terrorismo, como professores de hoje fazem (DeCesare, 2004b). Naquela época, estes simplesmente não eram os problemas iminentes que eles são hoje. Talvez seja um truísmo dizer que os professores de sociologia em todos os níveis são constrangidos em termos de tópicos que eles cobrem por vezes em que vivem. Isso não significa, porém, que devemos ignorar esse ponto em nossos estudos de como a disciplina é ensinada e por isso que é ensinado assim.

Uma previsão final:

4) Embora alguns dos primeiros sociólogos pudessem tomar para si a realização de estudos de pequena escala do status da sociologia no Ensino Médio, os seus colegas - a grande maioria dos sociólogos - vão continuar a ignorar o tema.

Não é nenhum segredo que há uma falta de interesse generalizada e de longa data entre os sociólogos acadêmicos na sociologia no Ensino Médio (DeCesare, 2002a; DeCesare; Lashbrook, 2004). Talvez isso não deva vir como uma surpresa. Afinal, a maioria dos sociólogos profissionalmente treinados ensina em faculdades ou universidades. Eles, portanto, não se sentem responsáveis, nem se interessam, pelo estado da disciplina no ensino secundário. Além disso, a ênfase de longa data na sociologia - e na academia, em geral - tem sido e continua a ser sobre pesquisa, em vez de ensinar. Essas duas características da sociologia americana contemporânea têm trabalhado contra a geração de qualquer interesse pela sociologia do Ensino Médio entre os sociólogos acadêmicos. Não me parece que essas tendências vão mudar tão cedo.

Em resumo, eu não tenho nenhuma razão para acreditar que os cursos de sociologia do Ensino Médio vão parecer muito diferentes em 2015 ou 2025 do que parecem agora. Nos próximos anos, os professores enfrentarão as mesmas restrições estruturais sobre o ensino de sociologia no contexto escolar, e provavelmente eles vão ser tão despreparados como os professores de hoje para oferecer uma versão mais científica da sociologia a seus alunos. Da mesma forma, o AAS vai continuar a agarrar-se à sua crença de que a sociologia é uma ciência, pois sem a respeitabilidade intelectual que a ciência concede, nosso status como uma disciplina entra em questão. Basta olhar para a proposta curricular de estudos sociais do Ensino Médio da Força Tarefa do AAS para 
perceber que o grupo está empurrando a sociologia científica na escola, ignorando completamente o contexto em que os professores trabalham. E sociólogos, por sua vez, provavelmente terão nenhum incentivo intelectual, de carreira ou pessoal para prestar atenção às salas de aula do Ensino Médio.

Se a história do ensino de sociologia na escola demonstra alguma coisa, é isto: há razões sociológicas tanto para a ação individual quanto para a inação. Cabe aos sociólogos prestar muita atenção a eles durante os próximos 100 anos de ensino de sociologia no Ensino Médio.

Recebido em 06 de março de 2013

Aprovado em 03 de dezembro de 2013

\section{Anexos}

ANEXO A - Esboço do Curso de Bate (1915, p. 337-340)

I. Introdução

II. Instituições da Sociedade

III. A Família

IV. Crescimento da População

V. População nos Estados Unidos

VI. Imigração

VII. O Problema da Cidade

VIII. Trabalho Infantil

IX. Pobreza e Pauperismo

X. Dependentes e Deficientes e seus Cuidados

XI. Crime e suas Punições

XII. O problema da Bebida

XIII. Educação e Progresso Social

XIV. Conclusões e Resumo do Curso

O esboco de curso termina com uma nota sobre um outro problema social: "Quando este curso foi ministrado no centro de Illinois, o tema 'O Problema Negro’ foi incluído, mas é omitido agora” (Bate, 1915, p. 340).

\section{ANEXO B - Bibliografia de Fuchs (1970)}

ABRAMS, Charles. 1965. The City is the Frontier.

ASHLEY, Montagu M.F., ed. 1969. Man and Aggression.

BECKER, Howard S. 1963. Outsiders.

BERGER, Peter L. 1963. Invitation to Sociology: A Humanistic Perspective.

BLAU, Peter M. 1956. Bureaucracy in Modern Society.

CAUDILL, Harry M. 1962. Night Comes to the Cumberlands.

CUZZORT, R.P. 1969. Humanity and Modern Sociological Thought.

Educação \& Realidade, Porto Alegre, v. 39, n. 1, p. 113-137, jan./mar. 2014. 
DOMHOFF, G. William. 1967. Who Rules America?

EVANS, Robert R., ed. 1969. Readings in Collective Behavior.

FESTINGER, Leon, Henry W. Riecken, and Stanley

SCHACHTER. 1956. When Prophecy Fails.

GANS, Herbert J. 1962. The Urban Villagers.

GLAZER, Nathan, ed. 1970. Cities in Trouble.

GOFFMAN, Erving. 1959. The Presentation of Self in Everyday Life.

GRAHAM, Hugh Davis and GURR, Ted, eds. 1969. Violence in America.

HAMMOND, Phillip E., ed. 1964. Sociologists at Work: Essays on the Craft of Social Research.

HUGHES, Helen MacGill, ed. 1970. Cities and City Life.

LEMERT, Edwin M. 1967. Human Deviance, Social Problems and Social Control.

LIEBOW, Elliott. 1967. Tally's Corner.

LIPSET, Seymour M., Martin Trow, and James Coleman. 1956. Union Democracy.

MADGE, John. 1962. The Origins of Scientific Sociology.

MILLS, C. Wright. 1967. The Sociological Imagination.

POLSKY, Ned. 1969. Hustlers, Beats and Others.

RUBINGTON, Earl and Martin S. Weinberg, eds. 1968. Deviance.

SCHUR, Edwin M. 1965. Crimes Without Victims.

SUDNOW, David. 1967. Passing On.

THOMLINSON, Ralph. 1965. Sociological Concepts and Research.

WARNER, Sam Bass, Jr., ed. 1966. Planning for a Nation of Cities.

WHYTE, William Foote. 1965. Street Corner Society.

WINCH, Robert F. and Louis W. Goodman, eds. 1968. Selected Studies in Marriage and the Family.

\section{Notas}

10 primeiro curso de sociologia geralmente é entendido como tendo sido oferecido por William Graham Sumner na Universidade de Yale em 1876 (Bernard; Bernard [1943] 1965; Grier, 1971). Há algum desacordo sobre a data e até mesmo sobre o professor, no entanto Bernard (1909) coloca a data do curso em 1873, e mais tarde afirmou que o próprio Sumner usou essa data (Bernard, 1945). Campbell (1985) difere de todos, afirmando que Albion Small ofereceu o primeiro curso na Universidade de Yale em 1875.

$2 \mathrm{~N}$. T.: ainda que linguisticamente falando a palavra college do inglês possa ser traduzida como colégio em português, uma vez que ambas derivam da mesma palavra latina (collegium), deve-se fazer a ressalva de que nos Estados Unidos essa palavra é utilizada para se referir, de forma genérica, ao ensino superior, mais especificamente aos estudos em nível de graduação, por isso optamos aqui por traduzir como faculdade.

3 Eu gostaria de agradecer a um dos revisores por levantar a questão crucial de padrões acadêmicos estaduais e para a prestação de informações sobre as normas atualmente em vigor na Pensilvânia. 
4 N. T.: o Advanced Placement (AP) é um programa criado pelo College Board, que inclui tanto a elaboração de currículos para o Ensino Médio por uma série de especialistas, quanto exames realizados junto aos egressos desta modalidade de ensino, o que é amplamente aceito e utilizado como teste admissional em várias instituições de Ensino Superior nos Estados Unidos.

5 N. T.: o College Board é uma associação sem fins lucrativos nos Estados Unidos que vende testes de admissão usados pelas universidades com a finalidade de medir a habilidade de um estudante.

\section{Referências}

AMERICAN SOCIOLOGICAL ASSOCIATION. Draft AP Sociology Curriculum. Washington, DC: American Sociological Association. 2004. Disponível em: <http://www.asanet.org/members/apsoccur.pdf>. Acesso em: 01 ago. 2004.

ANGELL, Robert C.. Sociology Instruction, Secondary Schools. In: DEIGHTON, Lee C. (Org.). The Encyclopedia of Education, v. 8. New York: Macmillan, 1971. P. 308-311.

BAIN, Read. Sociology in Washington High Schools. The School Review, Chicago, n. 34, p. 535-542, 1926.

BATE, W. G. An Experiment in Teaching a Course in Elementary Sociology. The School Review, Chicago, n. 23, p. 331-340, 1915.

BERNARD, Luther L. The Teaching of Sociology in the United States. American Journal of Sociology, Chicago, n. 15, p. 164-213, 1909.

BERNARD, Luther L. The Teaching of Sociology in the United States in the Last Fifty Years. American Journal of Sociology, Chicago, n. 50, p. 534-548, 1945.

BERNARD, Luther L.; BERNARD, Jessie. Origins of American Sociology: the social science movement in the United States. New York: Russell and Russell, [1943] 1965.

BOHLKE, Robert H. The Teaching of Sociology in Secondary Schools: problems and prospects. Social Forces, North Carolina, n. 42, p. 363-374, 1964.

BUROKER, A. B. Sociology in a Rural High School. The Historical Outlook, Philadelphia, n. 11, p. 151-152, 1920.

CAMPBELL, Frederick L. Turning toward Teaching. In: CAMPBELL, Frederick L.; BLALOCK JR., Hubert M.; MCGEE, Reece. Teaching Sociology: the quest for excellence. Chicago: Nelson-Hall, 1985. P. 3-22.

DECESARE, Michael A. The Lesson to be Learned: the past troubles and future promise of Teaching High School Sociology. Teaching Sociology, v. 30, p. 302316, 2002a.

DECESARE, Michael A. Locating the State of High School Sociology on the Academic Map. Footnotes, Washington D.C., v. 30, n. 2, p. 9, 2002 b.

DECESARE, Michael A. "Apathetic, Active, or Antagonistic": a history of the American Sociological Association's Involvement in High School Sociology. The American Sociologist, n. 35, p. 102-123, 2004a.

DECESARE, Michael A. Preaching Science or Promoting Citizenship? Teaching Sociology in High School. Ph.D. dissertation, Department of Sociology, University of Massachusetts, Amherst, MA. 2004b.

DECESARE, Michael A. The High School Sociology Teacher. Teaching Sociology, v. 33, n. 4. No prelo. 
DECESARE, Michael A.; LASHBROOK, Jeff. The Status of High School Sociology: Some Recommendations. Footnotes, Washington D.C., v. 32, n. 4, p. 5-6. 2004.

DENNICK-BRECHT, M. K. A Status Report on Introductory Sociology Courses in Public High Schools in Pennsylvania. Ed.D. dissertation, School of Education, Duquesne University, Pittsburgh, PA. 2000.

DORN, Dean S. High School Sociology: a view from California. Footnotes, Washington D.C., v. 14, n. 4, p. 13-4, 1986.

DOWELL, Edward S. Course in Sociology Offered in the Bucyrus High School. The Historical Outlook, Philadelphia, n. 12, p. 318-323, 1921.

DYER, J. Pope. Vitalizing Sociology Instruction. The Social Studies, n. 24, p. 1920, 1938.

DYER, J. Pope. Modernizing Sociology Teaching. The Social Studies, n. 40, p. 305-306, 1949.

FLICK, O. S. Problems and Methods in the Teaching of Economics and Sociology in the High School. The Historical Outlook, Philadelphia, n. 24, p. 254-259, 1933. FUCHS, John. \$100 Worth of Readable Paperbacks for High School Sociology. Top of the News, n. 27, p. 57-65, 1970.

GILLETTE, John M. Sociology as a High School Subject. The Educational Review, n. 45, p. 256-262, 1913.

GRIER, Lee W. The History of the Teaching of Sociology in the Secondary School. Ed.D. dissertation, Department of Education, Duke University, Durham, NC, 1971.

HAWKINS, E. E. New Viewpoints of Sociology. The High School Teacher, n. 6, p. 229-233, 1930

HAYES, Edward C. The Contribution of Sociology to Secondary Education. American Journal of Sociology, Chicago, n. 28, p. 419-435, 1923.

HINKLE, Roscoe C.; HINKLE, Gisela J. The Development of Modern Sociology: its nature and growth in the United States. New York: Random House, 1954.

HOTCHKISS, Grace E. The History of Sociology in the High School. The Historical Outlook, Philadelphia, n. 20, p. 402-404, 1929.

HURD, R. C. Sociology, by Project and Problem. The Historical Outlook, Philadelphia, n. 21, 265-266, 1930.

KERCHER, Leonard C. Recent Studies of Sociology in the Public High Schools of Michigan. The Journal of Educational Sociology, n. 11, p. 423-436, 1938.

KRAFT, James D. High School Sociology in Wisconsin: a troubled discipline. Wisconsin Sociologist, n. 18, p. 65-71, 1981.

LASHBROOK, Jeff. Sociology in High School: a profile of New York State. Teaching Sociology, n. 29, p. 354-359, 2001.

LEVINE, Felice J. The K-12 Pipeline in Sociology. Footnotes, Washington D.C. v. 25, n. 1, p. 2, 1997.

MASON, Florence. The Teaching of Sociology in High School. Journal of Applied Sociology, n. 8, p. 37-43, 1923.

NOURSE, Walter L.; BROWN, William B. Sociology and New Curricula. The Journal of Educational Sociology, n. 13, p. 411-418, 1940.

OBERSCHALL, Anthony. The Institutionalization of American Sociology. In: OBERSCHALL, Anthony (Org.). The Establishment of Empirical Sociology: studies in continuity, discontinuity, and institutionalization. New York: Harper and Row, 1972. P. 187-251.

136 Educação \& Realidade, Porto Alegre, v. 39, n. 1, p. 113-137, jan./mar. 2014 Disponível em: <http://www.ufrgs.br/edu_realidade> 
REPKE, Arthur. Sociology for High Schools. Sociology and Social Research, North Carolina, n. 44, p. 37-41, 1959.

RIENERTH, Janice et al. Sociology and High School Teaching. The American Sociologist, n. 29, p. 64-77, 1998.

ROBERTS, Hugh. High School Sociology: a study in social and human relations. American Sociological Review, n. 33, p. 673-674, 1968.

ROBERTS, Keith A.; PIKER-KING, Kathleen. Teaching Sociology in High School: a guide for workshop organizers. Washington, DC: American Sociological Association, 1995.

SCHALL, James H. Sociology in the High School Curriculum. Social Education, v. 29, p. 296-298, 1965.

SEPERSON, Susanne B. What's Wrong with Sociology? Its Public Image. Sociological Forum, n. 10, p. 309-312, 1994.

SHORT, Alvin P.; MATLOCK, Donald T. Sociology Programs in U.S. High Schools: current findings with a national sample. Teaching Sociology, n. 9, p. 313$322,1982$.

SHORT, Alvin P.; MATLOCK, Donald T.; WATTS, W. David. High School Sociology in Texas, 1984-85. Texas Journal of Science, n. 38, p. 25-32, 1986.

SHORT, Alvin P.; WATTS, W. David; MATLOCK, Donald T. Sociology in the High School: Perceptions of Those Who Teach It. Sociological Spectrum, n. 6, p. 211219, 1986.

SWINTON, Wayne. A High School Course in Sociology. The Social Studies, n. 31, p. 89, 1940.

SWITZER, Thomas J. Teaching Sociology in K-12 Classrooms. In: WRONSKI, S. P.; BRAGAW, D. H. (Org.). Social Studies and Social Sciences: a fifty-year perspective. Washington, DC: National Council for the Social Studies, 1986. P. 124138.

WATSON, Bruce A. Sociology in the High School. Sociology and Social Research, n. 39, p. 177-178, 1955.

WEBER, Marlene. Sociology in the Secondary Schools of Wisconsin. Wisconsin Sociologist, n. 15, p. 6-13, 1978.

WEST, John C. An Analysis of Senior High School Sociology. Ed.D. dissertation, University of North Dakota, Grand Forks, ND, 1930.

Michael DeCesare é Ph.D. em Sociologia pela Universidade de Massachusetts, professor do Departamento de Sociologia do Merrimack College, Estados Unidos.

E-mail: decesarem@merrimack.edu

Tradução de Amurabi Pereira de Oliveira 